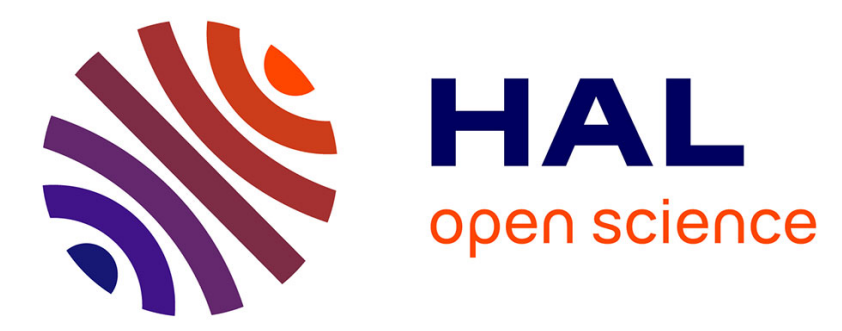

\title{
Rethinking "Impact": Between the Attention Economy and the Readerless Republic of Letters \\ Yves Citton
}

\section{To cite this version:}

Yves Citton. Rethinking "Impact": Between the Attention Economy and the Readerless Republic of Letters. SubStance, 2013, 130, pp.69-81. hal-00846468

\section{HAL Id: hal-00846468 \\ https://hal.science/hal-00846468}

Submitted on 19 Jul 2013

HAL is a multi-disciplinary open access archive for the deposit and dissemination of scientific research documents, whether they are published or not. The documents may come from teaching and research institutions in France or abroad, or from public or private research centers.
L'archive ouverte pluridisciplinaire HAL, est destinée au dépôt et à la diffusion de documents scientifiques de niveau recherche, publiés ou non, émanant des établissements d'enseignement et de recherche français ou étrangers, des laboratoires publics ou privés. 


\section{« Rethinking "Impact": Between the Attention Economy and the Readerless Republic of Letters », SubStance n ${ }^{\circ}$ 130, vol 42:1, 2013, p. 69-81.}

\section{Yves Citton}

\section{Rethinking "Impact" between the Attention Economy and the Readerless Republic of Letters}

Time is in short supply, so my argument will be condensed, and therefore apparently dogmatic. I will sketch seven reasons why we should distance ourselves both from the promotion of "impact" as an appropriate measure of a scholar's output and from its knee-jerk rejection as a scandalous, oppressive and humiliating form of control of scholarly work ${ }^{1}$. My main points will be that we all crave for impact (very understandably so), that the current definition of "impact" tends to hide what it claims to reveal (and should therefore be rejected), but, more importantly, that the very framing of "impact" rests on an obsolete conception of how and why we do research. To put it bluntly: we still hang on to the traditional idea that articles and books are made to be read (by a maximum of people), whereas we should accept the fact that they are mostly made to be written-independently of who does or does not end up reading them.

1. It's the economy, stupid! "Impact' is the buzzword of the day", Martha Nussbaum recently wrote recently in a much celebrated essay, "and by 'impact' the government means above all economic impact", Over the last twenty years, a number of procedures have been set in place throughout the academic world, from Harvard to London, then from Shanghai to Paris, attempting always more precisely (and more byzantinely) to measure researchers' output. From the emergence of the Publish or perish rule of survival in the US academic jungle to the rigid ranking of French periodicals into three classes of "excellence", and all the way to the precise calculation of each individual researcher's "H-factor", our age seems obsessed by a contradictory urge to produce as much scholarly writings as possible, and simultaneously to expect all these writings to "excel".

As the "buzzword of the day", "impact" translates into two categorical imperatives: Write (as much as you can) and Be read (by as many influential readers as you can reach). These two imperatives are overdetermined by conventional economics on at least three levels. First, as Martha Nussbaum writes, a number of evaluations of scholarly production come from governmental agencies, which tend to reduce research to the "Research and Development" model of technological innovation: universities are conceived as incubators of "new ideas" ready to be appropriated by investors eager to provide jobs and profits to fuel (or jump start) economic growth. While this expectation of macroeconomic impact might make some sense for certain fields of research (nanotechnology, solar energy, etc.), many other fields of academic inquiry feel trapped in a model that threatens and denies their very existencehence the success of Martha Nussbaum claim that the Humanities are Not for Profit.

\footnotetext{
${ }^{1}$ I express my gratitude to Marianne Dubacq, Christopher Newfield and Éric Méchoulan, who triggered and fueled my reflection on this topic.

${ }^{2}$ Martha Nussbaum, Not for Profit: Why Democracy Needs the Humanities?, Princeton University Press, 2010, p. 128.
} 
At a second deeper level, "impact" is framed by economic reasoning insofar as it comes down to a matter of accounting. Whether in nanotech or in 18th-century French literature, doing research costs money (if not in labs and fancy machines, at least in salaries). Universities have to measure their input (paying for buildings, libraries, heating, cleaning, staff, etc.), so it is not totally unreasonable to attempt to measure their output (degrees granted, patents obtained, papers and books published, etc.). At this accounting level, "impact" attempts to measure the effective output generated by academic institutions, in a "cognitive" phase of capitalism where universities have taken over the role previously played by factories in the age of "industrial capitalism".

At a third more fundamental level, the buzzword of "impact" expresses the total colonization of our mind by the logics of economic productivism. Social beings do not exist in the virtue of what they are, but through what they produce (within an ontological imperative according to which production is bound endlessly to "grow"). More to the point, their production can only be accounted for through market value. The evaluation of a researcher's output will therefore consist in putting a number on his or her contribution to our economic growth. Certain civilizations valued the sheer existence of "masters", secluded in out-of-the-way temples, absorbed in self-sufficient wisdom; ours values not so much the sharing as the profiting from the cognitive capital it has accumulated. Science and wisdom are not ends in themselves, nor even the keys to a better (individual and collective) life; they are means of production geared towards the maximization of economic growth.

"Impact" is the name of these three superposed layers of productivist expectations applied to academic research. It should be seen as part and parcel of a long-term trend of economization of our Western civilization, which started around the beginning of the $18^{\text {th }}$ century. It is very easy for politicians and university administrators to state the obvious to those who resist against the new procedures: It's the economy, stupid! Yet, it is necessary for all of us to measure the particular form of stupidity inherent to the economic logic.

2. It's economic stupidity! The denunciations of the many absurdities of "impact" are certainly welcome, since the very mechanisms set in place to promote the production of "excellence" often tend to stifle it. With a few years of delay after the first whistle-blowing in the USA, French academics have recently been much inspired in their denunciations of the counter-productive nature of such mechanisms. As various governmental offices, independent agencies and newly "autonomized" universities subject all enseignants-chercheurs to countless new procedures of collective and individualized evaluation, many in the academic community have stood up to denounce the naked absurdity of Impact's new clothes.

Among countless other examples, Grégoire Chamayou delineated the various rules of behaviour expected from a scholar eager to maximize "impact": don't do research, write papers; slice your book into five articles; quote your friends so they quote you in return; become an academic "troller"; minimize your unproductive time (preparing classes, grading papers $)^{4}$. Christophe Genolini and his colleagues dug into the details of the mathematic formulas developed by the French ministry in order to adapt university funding to the productivity of individual researchers, uncovering that (in the Humanities) the change of status from "publishing" to "non-publishing" cost a research team 15032 euros". Such a

\footnotetext{
${ }^{3}$ On cognitive vs. industrial capitalism, see Yann Moulier Boutang, Cognitive Capitalism, New York: Verso, 2012, as well as the dossier published in the issue 39 of the journal Multitudes, entitled "Universités / Multiversitudes" (Winter 2009), available online on http://www.cairn.info/revue-multitudes.htm.

${ }^{4}$ Grégoire Chamayou, "Petits conseils aux enseignants-chercheurs qui voudront réussir leur évaluation", Contretemps, February 2009 (available online at http://www.contretemps.eu/interventions/petits-conseilsenseignants-chercheurs-qui-voudront-reussir-leur-evaluation)

5 Christophe Genolini et al., "SYMPA : dissection d'un modèle", 2009 (available online at http://christophe.genolini.free.fr/administration/aTelecharger/SYMPAdissectionDUnModele.pdf),
} 
change of status, however, can result from the simple fact that the demoted scholar was stupid enough to spend the past years working (hard) on preparing a scientific edition of an important text - an activity not rewarded within the criteria selected to quantify "impact".

It would be too easy to remind evaluators that the devil is in the details. Yes, the procedures of quantification and classification need to be improved, since, like it or not, they are here to stay. We may hope for our civilization to reduce its fanatic endorsement of the productivist madness which is currently leading us straight to the ecological abyss (for which the more appropriate motto might be Publish AND perish). In the meantime, we have to face (rather than deny) the fact that economics is our enduring religion, that some translation of our research activity in terms of "impact" will be imposed upon us, and that it is in our best interest to improve the current translations, which threaten stupidly to kill the very economy they were designed to boost ${ }^{6}$.

The punctual, marginal and progressive improvement of the procedures of evaluation, however, will not suffice. We need to take more distance and identify the imperative of "impact" within a broader civilizational context. In doing so, we need to come to terms with our own contradictions and ambivalence as scholars.

3. Gimme impact! Let's face it: we all crave for impact. Who in the academic community-apart from a few dozen "stars" towards whom we all look with much envy-is not deeply frustrated by the pathetic lack of impact our wonderful work has over society at large? Don't we all write our books and articles in order to be read, admired and cited by as many people as possible? Isn't it the very purpose of our work: to be "published", i.e. to "circulate among a public" as attentive and as wide possible?

The first and most important problem should therefore not be located in the stupid econometricians who miscalculate our impact, but in the lack of traction which prevents our individual and collective research to reach its potential public. Instead of turning our impotence into resentment and incrimination against those who simply reveal our powerlessness, instead of denouncing the absurd ceremonials of Impact's new clothes, shouldn't we rather look in the mirror and face the fact that we (the supposed Emperors of the world of Research) are disturbingly naked?

There certainly is as much to criticize and improve in the traditional way academics publish (and fail to publicize) their output as there is in the way this output is quantified by the new model armies of impact calculators. Never before did mankind have at its disposal so many data, analyses, debates, propositions. Never before has there been so wide a gap between what we could do collectively, if these mountains of information, reflections and debates were properly circulating among us, and what we actually fail to do, due to the frustrating shortcomings of our mediatic infrastructure, which largely excludes (or dramatically misrepresents) academic thinking within our current public and popular debates.

Some hope may be put in the development of the new media, whose emergence is likely to upset many entrenched (bad) habits and develop new (more inclusive) ones. It would be too hopeful, however, to expect the digital age spontaneously to reshuffle the cards in a way that would provide better and wider impact to the research that deserves it. For the World Wide Web only exacerbates an underlying problem which is at the unspoken root of most debates about "impact". It is again a problem of economy, but of a rather different type: the attention economy.

\footnotetext{
${ }^{6}$ For a very powerful and suggestive critique of the current mismeasurement of scholarly work in the Humanities, see Christopher Newfield, "Ending the Budget Wars: Funding the Humanities during a Crisis in Higher Education", Profession 2009, p. 270-284 as well as Unmaking the Public University. The Forty-Year Assault on the Middle-Class, Cambridge Mass., Harvard University Press, 2008.
} 
4. It's the attention economy! Over the past twenty years, coming from very diverse disciplines (marketing, psychology, management, sociology, political science, rhetoric, art history), several important publications have prepared the ground for a major rethinking of conventional economic theories ${ }^{7}$. Economics as we know it is in charge of maximizing the production of goods within conditions of scarce resources. As the $20^{\text {th }}$ century has developed a society of "affluence" for at least a quarter of world population, our relation to scarcity has progressively evolved. In the old days (and in many parts of our current world), the economic worry consisted in producing more "stuff", so that more of our basic (material) needs could be satisfied. Those who talk about an "information society" often substitute a scarcity of information for a scarcity in material goods. But, as Richard Lanham noted, "information is not in short supply in the new information economy. We're drowning in it. What we lack is the human attention needed to make sense of it all"8. In our information-affluent societies, the new scarcity is no longer material goods, nor information itself, but attention: the time and capacity to plug one's mind to a certain source of mental stimuli, within the context of a distressingly superabundant supply of available stimulations.

We cannot make any sense of the issue of "impact" without taking into account this new context provided by the attention economy. We are bound to live in a world of superabundant information. It is not an offense, nor a humiliation, nor a disgrace to publish without being read: it is ever more likely to become our common fate-frustrating as it may be. The tables should be turned: we must learn to consider it a very special favor, a blessing, a true grace, to have anybody pay any attention to what we publish. We keep imagining "the public" (whether we refer to the grand public tuned to mainstream media, or to the small circles of our colleague scholars) as an attentive hunter, eager to jump on any catchy innovation rearing its head from the most hidden corners of the forest. We should learn to consider our newly published book or article for what it really is: a message in a bottle, thrown into a wide ocean saturated with floating debris.

The status and measurement of "impact" are to be drastically reconsidered within the current attention economy ${ }^{9}$ : for a text to meet a reader should not be considered a minimal requirement, but a miracle. And even in our age used to winner-take-all policies, it appears as unfair, cruel and absurd to use the good fortune enjoyed by some blessed members of the academic community, in order to sanction those who weren't lucky enough to win the attention lottery.

\footnotetext{
${ }^{7}$ For basic references on the attention economy, see for instance Michael Goldhaber, « Attention, Meaning, and Meaningfulness », available on http://www.well.com/user/mgoldh/attmean.html, 1996; Philippe Aigrain, «Attention, Media, Value and Economics », First Monday, 2: 9-1, September 1997; Jonathan Crary, Suspensions of Perception. Attention, Spectacle and the Modern Culture, Cambridge, MA: MIT Press, 1999; John Beck \& Thomas Davenport, The Attention Economy, Harvard Business School, 2001; Jonathan Beller, The Cinematic Mode of Production. Attention Economy and the Society of the Spectacle, Hanover: Dartmouth College Press, 2006; Franco Berardi, The Soul at Work, Los Angeles: Semiotext, 2009; Dominique Boullier, "Les industries de l'attention : fidélisation, alerte ou immersion", Réseaux 154: 2009-2.

${ }^{8}$ Richard Lanham, The Economics of Attention. Style and Substance in the Age of Information, University of Chicago Press, 2006, p. xi.

9 Of course, one could accumulate quotes dating back to Antiquity, where authors complain about the overcrowding of the publishing scene. Renaissance writers were merely imitating Latin authors when they expressed their frustration to see sheets pulled from their unforgettable work used to wrap smelly fish in the market. Enlightenment thinkers, Romantic poets and avant-garde novelists have joined a similar chorus, deploring the superabundance of "low" entertainment which deprived their "high" art from its deserved audience. The true novelty of the attention economy is not to be found in such subjective feelings and deplorations, but in the sheer number of people involved in reading and writing, in the increasing disproportion between what is available and what can be read, and in the new plasticity of our social organizations towards the orientation of our collective attention.
} 
Dominant approaches to the attention economy are geared towards marketing and management. Their goal is to help individual players win the lottery: how to catch readers' attention? How to keep it? How to transform it into action (in terms of consumerism, management or political activism)? Scholars eager to increase their $\mathrm{H}$-factor would certainly be well-advised to read this management and marketing literature (although it rarely goes beyond what the Monty Python aptly named "the bloody obvious"). But the intellectual ecosystem affected by issues of "impact" needs to be approached as a whole, beyond individualistic and opportunistic lines of flight. For it is the very notion of "impact" which should be called into question, and ultimately rejected, in light of our current attention economy.

5. Impact and the shock doctrine. In its most basic manifestations, the attention economy is a matter of catching people's eyes and ears, of short-circuiting argumentative chains, and of triggering a desired reaction in members of the audience. From this point of view, "impact" is only one of the many rhetorical weapons pulled out of the administrative bag when it comes to slashing budgets, increasing teaching loads, freezing hires, or closing whole departments - all in the name of "the Economy". Other civilizations erected Holy Prophets, oracles, Aristotle, the Koran or a Sun King as the ultimate source of Authoritysince no civilization can function without its master-signifier (Lacan), its final vocabulary (Rorty), its "factishes" (Latour). Although our Economic Idol is being shaken on its feet, it is still playing its regulating role which, like the Holy Prophets', the oracles', Aristotle's, the Koran's, the Sun King's and all other factishes', does have its functional necessity. Within our current systems of beliefs and modes of argumentation, actions are made acceptable by being budgeted, budgets are designed by quantifying input and output, and therefore outputs need to be measurable, visible, palpable. "Impact" is the name of a scholar's palpable output.

Of course, unbelievers could ask disturbing questions: why do we need precisely to measure the social impact of a research program in $18^{\text {th }}$-century French literature, while nobody even thinks of measuring the social impact of an advertisement campaign for SUVs? Here again, instead of rejecting the question of impact as offensive, disrespectful and irrelevant, academics should reclaim it forcefully-and call for every profession to be subjected to a rigorous evaluation of its measurable effects on our common social life. Such a heretic broadening of the notion and use of "impact" would reveal two of the essential hidden assumptions which make it such a deceptive weapon in the hands of our accounting priests eager to sacrifice the Humanities on the altar of Economic Necessity.

First, it would reveal a very general and dramatic blindness affecting all of our conventional economic calculations: our sacred obsession with growth (as measured by the holy number of the GDP) prevents us from asking questions about the direction in which we want our economies to grow ${ }^{10}$. Advertising campaigns for SUV certainly have some sort of impact over their audiences and over our economy at large. The true (but rarely asked) question is: does this impact push us in the right direction? Here again the academic community could turn the tables and say: "Gimme impact any day, and let's compare where our various activities push us collectively!"

Second, a more careful reflection on how academic research pushes us in what direction would reveal the profound impropriety of the very notion of impact. An impacted object is set in motion, transpierced or destroyed through some sort of shock. The current administrative accounting of "impact" metaphorically projects us in an imaginary of bullets, shrapnel and car crashes,-well attuned to Hollywood blockbusters, but totally inadequate when it comes to understanding how academic inquiry really works.

\footnotetext{
${ }^{10}$ For a historical perspective on this disoriented reference to growth, see Yves Citton, Zazirocratie. Très curieuse introduction à la biopolitique et à la critique de la croissance, Paris: Editions Amsterdam, 2011.
} 
It is hard not to contextualize the impact frenzy within the broader script described by Naomi Klein as the Shock Doctrine. The High Priests of Economic Neoliberalism (Milton Friedman and his Chicago boys) have constructed a remarkably efficient political scenario wherein some form of initial shock (an earthquake, a flood, an epidemics, an economic crisis, a financial crash) is exploited to "reform" society, as if it could be reconstructed from a tabula rasa, on the sole basis of individualistic market-based exchanges ${ }^{11}$.

"Impact" owes some of its lure to the shock doctrine. A successful research project is supposed to shock the academic community into a new form of thinking: its ripple effects can be traced through the widening circles measured by citation indexes. Thomas Kuhn's changes of "paradigm", Schumpeter's "creative destruction", a tradition of "shock and awe" cultivated by modernist art, as well as some remnants of the 1960s "revolutionary" rhetoric can easily be mobilized to support an imaginary of catastrophes in charge of periodically regenerating the world of research. H-factors and impact calculations naturally complement the more traditional metaphors of "dead-wood" professors and indolent tenured civil servants, in portraying the academic world as a somnolent body, always in need of periodical electroshocks in order to remain awake. After the war on crime, the war on drugs and the war on terror, our tireless military imagination seized the imaginary of impact to invent yet another trigger-happy adventure: the war on dead wood.

6. Ecosystem, percolation, pandemonium and the decapitation of icebergs. What can be opposed to "impact", once it has been appropriately described as the name of the neoliberal restructuring of the academia? Some hope can be found in the social movements developed in France and across Europe in opposition to the concrete measures set in place to implement the measurement of impact (mainly through a refusal to fill out the forms provided for evaluation). But we also need a broader perspective and an alternative model, in order to counterbalance the persuasive weight of the shock doctrine. This alternative model could be built on at least three main points.

First, the individualistic approach (which underlies the whole construct of conventional economics) is fundamentally inept and inapt, when it comes to explaining and nurturing our collective capacity to innovate. Yes, inventions and creations result from unpredictable initiatives and bifurcations operated by individualistic monads, in a logic well described by sociologist Gabriel Tarde since the end of the $19^{\text {th }}$ century ${ }^{12}$. But such creative moves are only made possible by a "network" of relations (Latour), by the "biopolitical" power of "the common" (Negri and Hardt), by the particular properties of an intellectual, social and anthropological "medium" (Ingold) ${ }^{13}$. In other words: it takes a whole ecosystem for individuals to be able to do research.

Second, the constitutive process of this ecosystem rests on a slow percolation from below, rather than on the disturbance of periodical electroshocks. More precisely: in order to have any impact on a system, electroshocks need a structured medium for their effects to ripple through the system. Apart from episodic moments of disturbance, the daily fabric of intellectual inquiry is powered by its capillary texture: its reactivity to any form of impact does not rest on the "excellence" of a few Nobelized stars and lottery-winners, but on the multiplicity of players ("losers" included). The structured medium of academic research

\footnotetext{
${ }^{11}$ Naomi Klein, The Shock Doctrine. The Rise of Disaster Capitalism, Toronto: Knopf, 2008.

${ }^{12}$ On Tarde, see Maurizio Lazzarato, Puissances de l'invention. La psychologie économique de Gabriel Tarde contre l'économie politique, Paris : Les empêcheurs de penser en rond, 2001 and Bruno Latour and Vincent Lépinay, L'économie, science des intérêts passionnés. Introduction à l'anthropologie économique de Gabriel Tarde, Paris : La Découverte, 2008.

${ }^{13}$ Bruno Latour, Reassembling the Social: An Introduction to Actor-Network-Theory, Oxford University Press, 2005; Antonio Negri and Michael Hardt, Commonwealth, Harvard University Press, 2009; Tim Ingold, Being Alive. Essays on Movement, Knowledge and Description, London: Routledge, 2011.
} 
works best when it is allowed to percolate from bottom up, i.e., when a multitude of individual and collective initiatives are given the time and the means to pursue their course, at the pace of their own singular dynamics.

Third, the collective form of intelligence responsible for the development of our current technoscience, while often steered from above by military agenda and political rivalries, has been fueled by a generally chaotic regime of parallel and redundant circuitry, which could be adequately described by the term of "concurrence" if that term had not been unduly restricted to the sole aspect of competition. Discoveries are made by a multitude of researchers, labs, programs working in parallel towards similar objectives: they "run together" (they "con-cur") in the same direction, sometimes sharing their latest results thanks to the establishment of collaborative structures, sometimes competing in a race for patent and fame, often simply ignoring each other's efforts. Redundancy allows for one's mistake or madness to be corrected by the others' common sense.

In a recent book describing how the human brain performs the amazingly complicated task of reading, Stanislas Dehaene appropriated Oliver Selfridge's image of the pandemonium to illustrate the simultaneous parallel firing of many neurons in charge of identifying the letters of a word. This "assembly of daemons", where each demon responds to one stimulus and where their parallel single-minded efforts generate a powerful form of collective intelligence, provides the best model to account for the complex mix of collaboration and competition involved in the nervous system. "Composed of close to one hundred billion cells, the human brain is the archetype of a massively parallel system where all neurons compute simultaneously. [...] The massive parallelism of the pandemonium results in a substantial gain of time. Each daemon accomplishes an elementary task by checking to what extent the stimulus letters match its target word"14.

Even if it would be simplistic to conceive collective intelligence as modeled on neuronal circuitry, the pandemonium structure provides a suggestive image of the dynamics of academic inquiry - an image well designed to counterbalance the lure of "impact", along with its idolatry of "excellence". If a zealous administrator of the pandemonium kingdom decided to reward only those "excellent" demons who got an accurate response over the previous cycle of shots, in order to demote the dead-wood demons and push them to early retirement, the whole dynamics of the pandemonium would rapidly grind to a halt. It is ironic to see policy-makers attempt to boost scientific inquiry by imposing the individualistic regime of impact and excellence at the very moment when researchers are beginning to understand the prevalence of "swarm intelligence" in countless domains of human activity. Collective intelligence works best when it operates as a swarm—tackling problems through multiple, parallel, often redundant moves.

"Impact" and "excellence" undermine the power of multiplicity, which is the effective source of our collective intelligence. The policies of evaluation, reward and punishment enacted under these catchwords amount to decapitating icebergs in order to collect only the "outstanding" members of the academic community-as if these members could "stand out" without being supported by the other members of the community. It takes an ecosystem to nurture research, as it takes a multitude to provide the benefits of swarm intelligence.

7. Towards a readerless Republic of Letters? One curious paradox of the swarm analogy is that the collective intelligence of the bees seems to emerge in spite of their relative indifference to each other's behavior. Members of a swarm-like multitude "feel" rather than know what the other members are currently doing. Each of the many demons of the pandemonium fires his shot without bothering to coordinate it with the others. The neuronal

\footnotetext{
${ }^{14}$ Stanislas Dehaene, Reading in the Brain. The New Science of How We Read, New York: Penguin, 2010, p. 4546.
} 
pandemonium allows us to read texts, even if none of the neurons attempts to find out what its neighbor is doing. Such is also the dynamic of the internet, which is only a very loose, simple and minimally coordinated structure, whose collective intelligence rests mostly on the computing power of the personal machines connected to it, as well as on the personal knowledge and curiosity of those who communicate through it ${ }^{15}$.

These very diverse forms of collective intelligence conspire to suggest the same puzzling conclusion, which goes against our most entrenched conceptions of scientific inquiry: reading each other's work may be less important for scholars than writing their own. The idolatry of Impact rests on the (apparently obvious) assumption that a book or an article produces its effects (its actual output) when it is read, and that these effects are directly proportional to the number of people who read and quote it. While there is certainly some truth to this assumption, it may be judicious, in conclusion, to try and scratch under the surface of this commonsensical self-evidence.

As noted earlier, the current academic policies expect each scholar to publish a maximum of papers (to boost her productivity factor), while simultaneously expecting these papers to be read and cited by a maximum of other scholars (to boost her impact factor). Add the fact that the number of scholars, programs, journals, publishing houses has exploded during the second half of the $20^{\text {th }}$ century (along with the unprecedented increase in enrollments in higher education), throw in the added requirement of fostering interdisciplinarity, which expects scholars to remain afloat in three or four disciplinary fields in parallel —and you'll have the basic mix of a striking conundrum: we are all so busy writing our papers that there is virtually no time left to read what the others are publishing.

Time is in short supply: this was the central point of my argument, which, condensed and dogmatic as it was, still devoured precious minutes of your attention. Under the pressure of maximizing your $\mathrm{H}$-factor, these precious minutes would probably have been invested more productively in writing your own paper. Economists call this the "opportunity cost", which measures what you are likely to gain from a given activity, in comparison with what could be gained from the other activities you chose not to perform instead. Affluent lives in affluent societies put an ever higher opportunity cost to any endeavour - with an ever higher price to pay in terms of psychological pressure, due to an ever more unbearable embarrassment of choices. As the number of journals, conferences, symposia, seminars, websites, distribution lists and social networks have exploded over the past decades, the opportunity cost of reading a given text tends to become infinite, threatening to crush the very possibility of reading ${ }^{16}$.

Reconsidered in the light of the puzzling workings of swarm intelligence, this growing disincentive to read may not be as absurd and as discouraging as it seems. Sending a message in a bottle need not be an act of desperation, as long as writing the message provides a selfsustaining experience. What if the collective dynamics of discovery benefitted more from scholars writing papers than from these papers being read by other scholars? The very imperative of "impact" would collapse as deceptive and misguided. The superabundance of virtually unread publications would be as much a cause to cheer rather as a source of frustration. The most radical theorists of democratic modernity dreamed of a society in which everybody would be an artist, a writer, a researcher, a scholar. With more than half a class age

\footnotetext{
${ }^{15}$ See Benjamin Bayart, “Comprendre la structure d'Internet pour comprendre son impact”, EcoRev' 47 (summer 2011), p. 10-15.

${ }^{16}$ Defenders of "impact" policies will rightly stress that the need to read our colleagues' work is cleverly built-in the impact machine, since familiarity with the current research constitutes a basic criteria for a paper to be accepted in a prominent (i.e., high impact) journal. Academic writing needs to display its readings in order to be validated by the academy - a fact which constitutes at the same time a catalyst and a barrier to innovation. For practical advice on how properly to refer to books one has not read, see Pierre Bayard's provocative essay: Comment parler des livres qu'on n'a pas lus?, Paris, Editions de Minuit, 2007.
} 
endowed with a Bachelor's degree, we may be well on our way towards such a highly desirable world, in which the creative drive is so equally and intensely shared that intellectual and artistic production is valued for itself, independently of the improbable encounter of a rarefied audience.

A readerless Republic of Letters may therefore not be a contradiction in terms. A pandemonium of parallel and largely redundant research programs, more absorbed in their own development than in reading their neighbors' results, may very well be the future towards which we are already steering full speed ahead, without facing the disturbing consequences of this common evolution. Research as an esoteric activity may be as valuable as the exoteric results it officially produces.

The perspective of a readerless Republic of Letters is nonetheless deceptive, because it rests on a simplistic alternative. On the one hand, the obsession of "impact" ties us to an obsolete conception of academic research, dominated by the figure of the reader. On the other hand, our productivist frenzy sketches the alternative landscape of an academic world dominated by the figure of the readerless writer. No single side of this binary choice is satisfactory.

We are neither bees nor demons. Reading obviously fertilizes our thinking and our research. Rather than choosing between "impact" and a freewheeling creativity oblivious of anything but itself, we need simultaneously to demand more time to read each other's work and the right to write readerless papers. Here again, the main obstacle to acquiring a clearer vision of the peculiar dynamics of scholarly work is to be found in our individualizing biases, which lead us to oppose the figure of the writer to the figure of the reader, while they are in fact two sides of a same coin.

An intelligent promotion of "impact" should therefore multiply fellowships designed to allow scholars to read each other's work-based on the principle that reading is as productive as writing. This would lead funding agencies to welcome a "measurable output" consisting in a one- or two-page list of books and articles read during the fellowship year. This is the type of impact policy most of us would highly welcome, as this would certainly do more to improve scholarly work than the miserable system of (heavy) sticks and (improbable) carrots officially devised to whip us into productive shape-but actually designed to justify the downsizing of our collective intelligence.

Within the small field of academic research as well as within the larger domain of our most basic social interactions, we face the same challenge to shelter our life forms from the productivist urge devised to optimize them. We need to prevent our competitive race towards prosperity from crushing our physical, social and mental life under the weight of a thoughtless economic maximization. Similarly, we need to prevent the competitive pressure of "impact" from crushing the very possibility of impact. 